\author{
Lorna Finlayson \\ ljfinl@essex.ac.uk
}

\title{
What To Do With Post-Truth
}

\section{Abstract}

Recent political developments have made the notion of 'post-truth' ubiquitous. Along with associated terms such as 'fake news' and 'alternative facts', it appears with regularity in coverage of and commentary on Donald Trump, the Brexit vote, and the role - relative to these phenomena - of a half-despised, half-feared creature known as 'the public'. It has become commonplace to assert that we now inhabit, or are entering, a post-truth world. In this paper, I issue a sceptical challenge against the distinctiveness and utility of the notion of post-truth. I argue, first, that the term fails to capture anything that is both real and novel. Moreover, post-truth discourse often has a not-fully-explicit political force and function: to 'irrationalise' political disaffection and to signal loyalty to a 'pre-post-truth' political status quo. The central insight of the speech act theory of J. L. Austin and others - that saying is always also doing - is as indispensable for understanding the significance of much of what is labelled 'post-truth', I'll argue, as it is for understanding the significance of that very act of labelling.

The term 'post-truth' is still relatively new, and often used without much consciousness or explicit explanation of its meaning. Those who employ the term (e.g. D'Ancona 2017) often distinguish it from more familiar categories such as lying or propaganda, or just plain falsehood. It makes perfect sense that they should try to do this. After all, lying is hardly a new phenomenon, either in general or in political contexts. The idea that politicians or the media began lying only in 2016 would 
be transparently laughable. So would any such claim of novelty as applied to the category of 'propaganda', which is probably associated most strongly with regimes of the early twentieth century, but which could also be identified, without obvious anachronism, as occurring far earlier - in principle, right back to the beginning of human societies. ${ }^{1}$ Less obviously untenable is the relative claim that lying - or propaganda, or falsehood - happens more in politics now than it used to at some more or less well-specified time in the past. Depending on how much of the past is included within the scope of the comparison, this could be either a very ambitious or a quite unexciting claim ("more than ever" vs. "more than last year"). Current talk of 'post-truth' typically purports to identify a rather recent and stark change - perhaps as recent as 2016. It is not obvious, however, that recent years have seen a radical increase in the amount of lying or propaganda in politics, sufficient to justify the rather grand-sounding assertion that we have entered a new era of 'post-truth'.

Perhaps in recognition of this - or perhaps just to insist on the distinctiveness of post-truth from these familiar categories - the proponents of 'post-truth' discourse sometimes state that what they are diagnosing is not (or not only) a change in the amount or nature of the mendacity and manipulation perpetrated by politicians, but a more profound and widespread shift in attitudes to the very ideas of truth and falsehood. Although this distinction is a potentially helpful one, the suggestion remains ambiguous and under-specified: what is this purported shift in attitudes, more exactly, and what is the evidence for its occurrence? In Section 1 below, I outline and briefly discuss three possible ways in which the post-truth thesis might be cashed out. Then, in Section 2, I draw on speech act theory in order to suggest an alternative reading both of the phenomena to which post-truth theorists are responding, and of that response itself.

\section{The post-truth thesis: three formulations}

What I am calling the 'post-truth thesis' is a claim to the effect that some kind of deep and significant shift has occurred - and has

\footnotetext{
${ }^{1} \mathrm{My}$ thought here is that propaganda in a broad sense - denoting any effort to manipulate opinion and sentiment so as to promote certain interests or projects - is an inevitable aspect of the power relations that structure any moderately complex human grouping.
} 
occurred quite recently - in people's relationship to truth. This purported shift is clearly regarded as a bad and deeply troubling development by those who detect it, and is often seen as linked to 'the rise of social media', 'echo chambers', 'identity politics', 'postmodernism' and various other scourges. I noted that the post-truth thesis, as it stands, is crucially underspecified. It is not always clear, for example, which people are meant to have changed their relationship to truth (for the worse). People in general? The poor? The young? It is often unclear, too, what the nature of this change in the relationship to truth is supposed to be, according to proponents of the thesis. This presumably varies from case to case, so that there is not a single 'posttruth thesis' but many. I also suspect that in many instances of its advocacy, the thesis is indeterminate - and, moreover, that it relies for its appearance of profundity and plausibility on preserving an ambiguity between two or more distinct propositions. I'll now outline the three which I take to be the most prevalent, whether implicit or explicit, in post-truth discourse.

\subsection{Hearts over heads ${ }^{3}$}

One proposition detectable within much post-truth discourse is a claim to the effect that people's beliefs - in particular, those relevant to politics - have lost their previous contact with reality. Simply put, people are wrong about politics - and wronger than has typically been the case. Now of course, the above-mentioned 'who'-question is raised here with some urgency. I've written elsewhere about the disproportionate focus on various politically dangerous delusions among poor or oppressed sections of the population (Finlayson 2019). Here, it will suffice to say that the group of those held to be more-thannormally-wrong about politics presumably does not include the proponent of the post-truth thesis, who laments the outbreak of wrongness, but does include certain 'populist' politicians and their

\footnotetext{
${ }^{2}$ Of course, this development pre-dates the emergence of 'post-truth' talk (and the events that triggered it) by many years.

${ }^{3}$ This one is for Tony Blair, who in July 2015 advised those whose hearts were with Jeremy Corbyn to 'get a transplant'. I won't focus on the pro-Corbyn movement in this paper. Some of what I say here may nevertheless be relevant for an analysis of the discourse around Corbynism, which, like Trump and Brexit, is a political phenomenon that has given rise to considerable consternation within the media and within liberal or 'centrist' circles.
} 
supporters. Not only are these people labouring under illusions, on this version of the post-truth thesis, but they have lost their sensitivity to truth or reality. In other words, it is not just that they happen to hold some false beliefs at the moment: their beliefs are systematically failing to 'track' the truth, and are instead responding to something else - such as emotion, or political 'fashion'.

This sort of thought is almost as familiar as the observation that politicians lie. As with the latter observation, we may disagree as to both the extent and the significance of the phenomenon. But however these are determined, it's once again far from clear that the phenomenon is new, or new to politics. What was going on in nineteenth-century Britain, for example, with regard to prevailing opinions on the abilities and proper roles of women, or colonised nonwhite people? J. S. Mill's point - for which he tends to receive an exaggerated amount of credit - was as simple as it was undoubtedly correct (although he only managed to apply it to gender, not race): a deep emotion and self-interest underlies patriarchal myths about women's 'nature'; the beliefs in question are often not sensitive to fact or argument, and this is what enables them to endure in the face of reason and countervailing evidence.

That belief is sometimes sensitive to factors such as emotion, rather than to truth or reality, ${ }^{4}$ seems as banal an observation as the one that notes that politicians lie. In the one case as in the other, the claim can be made less banal when it is rendered a relative one: it is not that this phenomenon of the distortion of political belief (by factors such as emotion) hasn't always occurred; but now, it happens on a radically grander scale. Again, though, it's not clear what warrants the relative version of the claim; and in order to make proper sense of it, we would need to know the geographical-historical scope of the intended contrast. Are people more wrong, politically speaking, now than in the nineteenth century? Slaves to their emotions in a way that their greatgrandparents were not? There may be respects in which this is so, but it is not obvious what they are or why we should think of them as outweighing what may be at least equally plausible candidates for areas

\footnotetext{
${ }^{4}$ This can be said without endorsing any general opposition between truth or 'reason' and emotion. Emotion can often enough be a source of truth (while what passes for 'reason' serves to mask it). But it seems difficult to deny that there are cases where emotion draws us away from truths which would, in the absence of that emotion, be apparent to us.
} 
in which people are less wrong and less beholden to emotion than was formerly the case. But as I've already observed, the term 'post-truth' is typically used to refer to a much more recent set of phenomena. Use of the term is associated less with simple nostalgia for past centuries than with a modified Whiggish view of history: society was progressing steadily towards ever greater enlightenment, rationality and freedom, until recently when - with the aid of such historically unprecedented innovations as social media - it all went horribly wrong, in a way emblematised by Brexit in Britain and by Trump in the US. The thesis is then that the explanation of the undesirable political trends in question is that people have stopped forming their opinions based on facts, and have fallen into the grip of emotional and irrational influences incubated by social media and other aspects of twenty-firstcentury life.

There is a simplistic logical sequence which could make the above thesis seem irresistible. Granted that the political events in question Brexit, the election of Trump - are indeed not only bad but worse (including relative to the interests of the people who voted for them) ${ }^{5}$ than the outcomes of electoral processes in the fairly recent past, then it seems to follow almost automatically that people have come to think and behave more irrationally - at least in political contexts - than they used to. But the degree of popular wrongness cannot be simply be 'read off the badness of elected outcomes in this way. Someone who votes to leave the EU because they do not trust the British political establishment (which is pressing vigorously for Remain) is not obviously more wrong in their political outlook than someone who votes Remain, thinking that our existing institutions are adequately rational and humane and broadly responsive to the interests and will of the population. ${ }^{6}$

\footnotetext{
${ }^{5}$ I am happy to grant this, and not only for the sake of argument. However, it should be noted that this is not to fall into the above-referenced tendency to invent or exaggerate the link between support for Brexit or Trump and poverty or membership of the working class. The middle-class rural Brexit vote, for example, still counts as irrational on what I take to be the plausible expectation - though falling short of certainty - that Brexit will lead to a worse form of life for the British middle class as well as for the rest of society (even if, as with most disasters, it will hit the worst off the hardest).

${ }^{6}$ You don't have to think anything like this to have voted Remain, of course (I don't and I did). The point is not about whether Remain was the right choice, but about the background views of which such choices may be symptomatic.
} 
In other words, what appears to some as an outbreak of mass hysteria may alternatively be seen as a confused and partial awakening; the recent past that many commentators yearn to have back, where things seemed moderately well-ordered and predictable, may be seen instead as characterised by either a kind of captive inertia or a deluded faith in a failed political consensus in thrall to neoliberalism. And if and to the extent that - or, perhaps better, in the respects in which - it may truly be said that people have lost have lost touch with reality and lost or given up the superior epistemic practices they used to employ, then this is at best a proximate cause of the sorts of events that preoccupy those who talk about post-truth. What is the further explanation for this sudden decline? At this point, something more substantial is needed than the customary vague mutterings about Facebook and 'echo chambers'. As soon as we start looking for it, we will quickly come upon the hypothesis that apparently erratic and irrational political behaviour might be down to decades of neglect, exploitation, and deceit by those in power. But once we contemplate that, it becomes harder to maintain an affirmative stance towards the world pre-'posttruth': all was not (even moderately) well; otherwise we wouldn't be in this situation. It may also become more difficult to uphold the idea that all this has taken place within a context that is meaningfully democratic - but in that case, it simultaneously becomes difficult to maintain that recent developments are a straightforward function or expression of 'public opinion'. In other words, this version of the post-truth thesis is in danger of multiple self-contradiction: to evidence the claim that people have recently departed from truth and surrendered themselves to emotion, a transition is invoked from a purportedly well-ordered state of affairs to a dysfunctional one; but in order to explain why people might do this - i.e. break from truth when previous practice was serving them quite well - we are in danger of admitting that things were not so well-ordered after all (thus the claim of a radical transition is abandoned or seriously watered down); once we admit that, we also lose or weaken the assumption of democracy, which was key to the analysis of recent political decline as a function of a decline or crisis in the epistemic competence of citizens. 


\subsection{Bullshit}

It is possible to be wrong - and also to be wrong because you are in the grip of a powerful emotion - while also caring about the truthvalue of your beliefs. That is, I may believe that $\mathrm{X}$ for emotional reasons and in the face of the evidence, but it can still be very important to me to believe that this is not the case - that X really is true, or at least warranted by the evidence available. Arguably, the concept of belief itself is such that believing that $X$ is equivalent to believing that $X$ is true. And the holder of various false beliefs may not only believe that those beliefs are true, but also think it a very important thing to have true and well-evidenced beliefs. Such a person, when confronted with truly overwhelming evidence, may be forced to abandon her belief that X. At the least, she will experience serious dissonance or difficulty in upholding her belief, since the evidence against its truth exerts a significant pull on her.

Some who employ the term 'post-truth' may take the view that the kind of person just described is not an illustration of what is meant by that term, but rather of normal human fallibility. On this version of the post-truth thesis, the claim is not just that humans are fallible in this way, nor even that their fallibility is currently manifesting itself in a particularly extreme way or on a particularly large scale. Its proponents claim to detect something qualitatively different, something that they interpret as a profound lack of interest in questions of truth or evidence. A person in this condition does not care whether her beliefs in general are true or false. On the assumption that, by definition, she believes of each individual belief she holds that it is true, then we may need to question whether certain of what appear to be beliefs are really that: perhaps she is simply fond of uttering certain statements, and acting 'as if she believed certain things to be true, without actually believing them to be true - yet not necessarily believing them to be false either. The charge then becomes that people have (more or less suddenly) become bullshitters, in Frankfurt's (2005) sense of the term: unlike liars (who know well that what they say is false, and want it to be so), bullshitters say what they say with no concern for whether what they are saying is true or not. This is often the formulation given in order to show what is significant and novel about the departure described by the label 'post-truth': people's being wrong, or lied to, or 
slaves to emotion, may not be new, but indifference to questions of truth or evidence is another matter.

This version of the post-truth thesis is certainly more distinctive, but what is its basis? There are a number of stock cases which tend to be adduced as support - for example, the incident in which Trump aide Kelly-Anne Conway responded to the uncovering of the administration's lie about the number of people present at a rally by stating that White House press secretary Sean Spicer had offered 'alternative facts'. Much has been made of this phrase, although the phenomenon of politicians deploying euphemisms when caught lying is pretty classic stuff ${ }^{7}$ (the main difference, arguably, is that the Trump administration is cruder and less experienced in - or just oblivious to - the 'rules of the game'). Bullshitting politicians may not be any newer than lying ones are (even as the style and vocabulary of both lies and bullshit changes over time), but recall in any case that the post-truth thesis supposedly identifies a shift in epistemic behaviour not (only) among politicians but on the part people more generally. In the present case, then, the relevant point is that when the Trump administration was caught lying - and this was not an isolated incident - his supporters didn't really care.

To infer from this kind of case an indifference to truth, however, seems at best too big a leap and a worst a simple confusion. What is clear from the case of the rally is that Trump supporters didn't really care how many people were there (or even that the administration lied). That, for them, was not the main point. What was important to them, presumably, was that Trump was going to tear up the rule book in order to 'make America great again': to deliver national pride and jobs and prosperity. There is no particular reason to think that they were indifferent to the truth-value of this proposition: those who thought it was false probably didn't vote for Trump. The mistake of some commentators was to assume that their targets must care about the things they supposed them to care about: with that assumption in place, the only explanation for their behaviour must be that they were so determined to believe (e.g.) that there were as many people at the rally as Trump claimed, that they were prepared to hold and spread the belief without interest in whether or not it was true - an analysis that

\footnotetext{
7 Think 'economical with the truth'.
} 
stretches the very idea of 'belief. Such a stretch might well be interesting and pertinent in some human contexts or cases - there are situations in which people seem to state and 'believe' things more in order to secure some effect than because of a conviction of truth - but such cases are not new (and this case is not very plausibly one of them).

Now take another well-aired example: Michael Gove's declaration, in the midst of a deceitful 'Leave' campaign in the run-up to the referendum that yielded Brexit, that people had 'had enough' of experts. Since our concern is with widely held attitudes rather than with the conduct of politicians in particular, we may leave aside the question of whether Gove himself is a bullshitter. The worry is that he was - is - right: that people have indeed had enough of experts. If so, this may be seen as symptomatic of a loss of interest in truth and evidence (of which experts are supposed to be a source): people do not care anymore whether the things they (at least profess to) believe, the things on the basis of which they act and vote, are true or well-supported by evidence. Again, however, this conclusion is itself wildly undersupported. Not trusting the testimony of those presented to you as experts is not the same as not caring about truth or evidence - and in fact, one obvious reason for not trusting or being interested in a given source is that you are interested in the truth and do not believe that the source in question will give it to you. Given the failure of economists to predict the 2008 economic crash - not to mention some spectacular public blunders by pollsters and political analysts more recently - the current mistrust of experts seems both understandable and, at least in some areas, entirely justified. This is not to deny that there are experts that deserve to be trusted but are not (and other sources that do not deserve to be trusted, but are). It is rather to help explain it: in an environment in which 'experts' have shown themselves to be so thoroughly untrustworthy, truly reliable sources are liable to get caught in the crossfire. But this is beside the main point. People may make unjustified, wrong, and sometimes disastrous decisions about where to place their trust. But failure to accept the epistemic authority of those whom society presents as 'experts' is not equivalent to a rejection of truth or evidence - it is a rejection only of a dominant view as to how and where these are to be sought. 


\subsection{Relativism}

The claims that people are ruled by their emotions and that they don't even care whether what they believe or say is true are often conflated, it seems to me, both with each other and with a third, yet more radicalseeming position: a so-called 'relativism' about truth, or even the view that there is no such thing as 'truth' at all. I'm anxious not to get too far into a discussion of relativism, since such discussion is frequently fraught and distracts from issues of greater importance, but suffice it to say, first, that 'relativism' is a word that gets bandied around far too casually, with little clarity about what is meant. Relativism, understood as the view that truth is relative to something (insert, for example: the speaker's own culture or society), is not the same as the view that there is no such thing as truth; rather, it is a revisionary view as to what 'truth' means or consists in. At least in many of its possible forms (these vary crucially according to what you insert after the 'relative to...'), relativism is generally regarded as an untenable position: not up for serious discussion, but occupying the lead role in many a reductio ad absurdum. However, relativism is also not to be conflated with the rejection of what I'll call 'positivism': the view that there are facts, mind-independent or 'antecedent', to use Dewey's term; that truth consists in the correspondence of our statements to those facts; and that we have (imperfect but significant) access to facts about the world through our senses, access which produces the material to support our knowledge claims. Pragmatists, for instance, reject this conception of truth and knowledge; but it does not mean that they are relativists, in any of the more usual senses of that term, nor that they hold each and every statement or opinion to be as true or 'valid' as any other (relativists don't even believe that, for the record, as it's just as possible for a statement to be false-relative-to- $\mathrm{X}$ as it is for it to be true-relativeto-X).

But anyway, why think that people have suddenly, en masse, become relativists? And what kind of relativists are they supposed to be, according to the post-truth hypothesis? I'll take these questions in reverse order. My impression is that when the subject of relativism is broached in the context of post-truth, the 'relativism' in question is one unknown to philosophers (or, perhaps, it is something closest to what is known to philosophers as 'subjectivism' and recognised only in 
particular domains such as ethics and aesthetics): this 'relativism' is the view that everyone gets to determine their own truth; what it means for something to be 'true' is simply that I have decided that it is true. In a way, this idea is not so different from that of indifference to truthvalue; but instead of professing not to care whether what you say is true or not, you simply redefine 'truth' in such a way as to help yourself to it.

What reason is there to think that a 'relativism' of this peculiar kind is endemic in twenty-first-century society? It's difficult to say very much about people's views on the philosophical question of the nature or status of truth, because in general people themselves do not say very much about it. ${ }^{8}$ As philosophers are usually quick to point out, views on the nature and availability of truth in various domains are distinct from so-called 'first-order' statements, which convey views about what is true in those domains. As Bernard Williams (2012) argues, for example, there is no good inference from cultural relativism in ethics the view that moral judgements are true or false only relative to the culture from which they issue - to any first-order moral claim, such as "We ought to be tolerant towards other cultures with different values from our own". Equally, first-order claims such as the claim that Trump will 'make America great again' do not obviously imply anything about the nature of truth or its role in politics. In order to support the diagnosis of a 'post-truth' era, cast as one in which people are dogmatically and narrow-mindedly attached to their own beliefs and utterly impervious to opposing views or contrary evidence, it is therefore necessary to look beyond the particular content of beliefs held, to the spirit in which they are held or the process by which they are thought to be formed.

It is here that the reference to 'echo chambers' becomes inevitable. The idea is that, thanks to modern technology, people are increasingly surrounding themselves only with what they want to hear or what they

\footnotetext{
${ }^{8}$ Philosophy students are a partial exception, since they are sometimes called upon to say something about philosophical questions about truth. Students of various subjects including philosophy do also have an annoying habit of saying that a given question is 'subjective', or describing their opinions as "true for me". But in my experience, this usually turns out to mean something much more straightforward, such as "I'm not 100\% sure", or "I don't know how to argue for my view", or "I think those with views other than mine deserve respect and not persecution".
} 
already believe, insulating themselves from challenges to their existing views and thus losing touch with the possibility that truth could lie anywhere else. Whatever we make of that suggestion, however, I can see little reason to interpret it as indicative of a commitment to relativism, as opposed to a more mundane narrowmindedness or insularity - and I'm not convinced that it's even indicative of the latter. There is not space here to say much of interest about this, but it strikes me that certain commentators are prone to get a little over-excited about the 'echo chamber' phenomenon. True, the format of political discussion and of campaigning, too, has changed - just as it changed with the advent of television. And there may be interesting things to be said about the nature of the change. But it is not plausible, I think, to suggest that the 'echo chamber' phenomenon is novel, or that it is the specific product of the social media age; nor is it realistic, in my view, to suggest that there is something inherently sinister about it. Even without (or before) social media, the way in which we form our views on politics as on other subjects resembles a self-maintaining weblike structure, knitted together out of bonds of trust: we first believe those closest to us (typically our immediate family); on the basis of what we take on trust from intimates, we then decide who else to trust or not to trust. Someone living in an age before Facebook nevertheless had family, friends, trusted sources (religious, academic, media), which could be pejoratively described - and quite possibly would be, by someone observing from an age in which some of these influences were no longer (or not yet) present - as something akin to an echo chamber or bubble.

Moreover, as political journalist Alex Nunns (2018: 214) has pointed out in the context of the rise of 'Corbynism' in the UK, social media is capable of performing an opposite function to that of the 'echo chamber':

With their own content [Corbyn's social media] team aimed to get people talking about the issues. This, they hoped, would overcome the so-called "echo chamber"- the tendency for people who agree to coalesce. This was more easily achieved on Facebook, where comments allowed for extended interaction, than Twitter. Sellers remember a particular example: a picture of Corbyn holding a banner saying "Stop scapegoating immigrants" got 10,000 shares on Facebook. "The first few comments were quite positive because they were the core support," he says. "Then when people shared it, a 
percentage of their friends weren't in our bubble and they started commenting negatively. And then other people would react to that and argue against them. [...] You could see there were those ripples, that it was going outwards, breaking outside of people that would normally be positive about immigration."

\section{How to do things with post-truth}

I've now looked at three formulations of the post-truth thesis. These are by no means supposed to exhaust the possibilities. But they are an attempt to capture what I take to be the ideas that are most commonly intended or implied by those who talk about post-truth. None of these formulations, I've argued, yields a post-truth thesis that both is plausible and points to something interestingly novel. That we are buffeted around by our emotions when it comes to forming beliefs is very plausible, even obvious; but that we are more like this now than a few years ago, it seems to me, is not. That people are generally indifferent to whether or not the things they believe about politics are true, or that they have subscribed to some individualistic form of relativism, seems implausible and unsupported by the stock examples.

To make these points, I have deliberately adopted a certain kind of flat-footed literalism. I've been treating the post-truth thesis in 'good faith': assuming that it is primarily to be understood as an attempt to say something about the world, and trying to determine what it could be saying. But that deals only with one dimension of speech. As emphasised by J. L. Austin and the tradition of 'speech act theory' he inaugurated, every 'saying' is also a 'doing'. In this final section, I want briefly to explore the implications of this insight for the current discussion of post-truth.

\subsection{Speech act theory}

Speech act theory seeks to issue a corrective to a traditional, unreflective view of what words do and what we can do with them. According to this traditional view, words are for saying things: we say things with words. As for doings, or actions, those fall into a separate category, which is only indirectly related to the category of sayings. By saying something, I may (sometimes) influence the way others think, and that may (sometimes) influence what they then go on to do. Conversely, the things that I and others do may lead to certain things 
being said about us. There is thus a causal exchange between the categories of sayings and doings: sayings respond to doings, and vice versa. The connection is never direct, however, but mediated through the mental processes of sayer and doer. And this mediatedness is adduced to ground an equally traditional view of freedom of speech, which says, in effect, that words are free but actions are not: a saying does not directly cause a doing (the doer cannot escape responsibility for the deed); saying is just a saying, and will not have direct effects on a world of flesh and blood. Moreover, the two categories do not overlap, except insofar as a saying technically and uninterestingly counts as one among many doings: we can do things with words, then, but the only thing we can do with them is say. The counter-claim of speech act theorists is that we can do far more with our words than this. ${ }^{9}$ In his 1961 book How to Do Things With Words, Austin makes a threefold distinction between three main kinds of act that we can perform with our words: 'locutionary' (the act of speaking certain words, e.g. "I do"), 'illocutionary' (an act performed in speaking those words, e.g. the act of marrying), and 'perlocutionary' (something which happens as a consequence of speaking certain words and thereby performing an illocutionary act such as marrying; for example, the perlocutionary act could be that of irritating the bride's family). ${ }^{10}$ These three categories and their interrelations are not important here, however. The point to take is just that there are, contra the traditional view, all sorts of things we can do with our words, above and beyond the locutionary act of saying: we can threaten, insult, flatter, undermine - and so on.

Why is this important? It depends on whom you're asking, but one very vivid case where the central insight of speech act theory has been put to work is in feminist philosophy, where it has been brought to bear on the debate over pornography and freedom of speech. ${ }^{11}$ To cut a long story very short: speech act theory allows us to notice that words

\footnotetext{
${ }^{9}$ As G. J. Warnock $(1973 ;$ 69-70) puts it, in a stunning example of the paradoxically convoluted clarity of some philosophical prose: "We have to consider, then, first, and if so when and why, to say something is to do something, in a sense, if there is one, in which to say something is not always, or even often, to do something, but is so only sometimes, in special cases."

${ }^{10} \mathrm{I}$ argue elsewhere (Finlayson 2014) that a sharp division between these three categories cannot be upheld, but for present purposes this doesn't matter.

${ }^{11}$ I discuss this debate at greater length in Finlayson (2014).
} 
- and other representations such as images - do not merely represent or 'say', but may actually do things to people, and that one of the things they may do to people is to affect what those people are and are not able to do with their words and representations; hence, the debate is not a simple clash between the value of freedom of speech and feminist concerns over women's treatment and safety, but rather a question of what speech is doing to whom (and to whose speech possibilities). I won't go further into these issues here either, however. A more general way of stating the benefit of treating sayings as doings is suggested by Margaret MacDonald: to ignore the dimension of speech as action is "to miss half its philosophical point and so is bad philosophy" (MacDonald 1941: 94). ${ }^{12}$

In the present case - the discourse surrounding post-truth - it seems to me that there are two levels at which the basic insight of speech act theory may be usefully applied. First, it might be applied in the analysis of the sorts of speech which are taken to be evidence for or instances of a post-truth mentality: the more notorious sayings about Trump, Brexit, or 'experts'. Those who speak of post-truth, I suggest, are sometimes guilty of overlooking the dimension of speech or expression as action, and thus are themselves trapped within the literalism I adopted for strategic reasons in the first part of this paper. Second, the insight can be applied to the speech that takes 'post-truth' as its object, so that the question becomes: what are people doing with their sayings about post-truth? I'll close with some brief remarks corresponding to each of these levels.

\subsection{Concluding remarks: speech act theory and post-truth}

It is clear that the notion of post-truth is employed to talk about popular speech and behaviour which the employer of that notion finds puzzling in their apparent deludedness or irrationality. 'Post-truth' is the label affixed to sayings which seem not to make much sense - to make so little sense, in fact, that a new concept is needed in order to capture the phenomenon. From this, wild leaps are made, inferring radical breaks with truth, or mass conversion to strangely radical philosophical positions. I've already argued, in Section 1 above, that

\footnotetext{
${ }^{12}$ MacDonald's point, it should be acknowledged, is not explicitly framed in terms of speech acts, but rather in terms of the causal origins and effects of even 'nonsensical' statements for political affairs.
} 
these inferences are too quick. I've also argued that the over-quickness is related to a failure to attend to the political and social background against which the purportedly bizarre epistemic behaviour is taking place. A further part of the picture, I want to suggest now, is a tendency to attend exclusively to the 'saying' dimension of the phenomena in question, at the expense of their status as 'doings'. For example, a vote for Leave in the Brexit referendum can be understood as a statement to the effect that Britain should leave the European Union, but it can also be understood as an act of defiance or provocation aimed at those in power. A statement about bananas can be understood as just that a statement about bananas - but it can also be understood as a more general declaration of allegiance and an expression of frustration. The specific content of the statement is sometimes not all that central to an appreciation of its meaning. This can help explain why the makers of the statements in question often seem impervious to refutation: it doesn't matter how many people were at the rally; the act of repeating and insisting on an inflated figure is, once again, a statement of affiliation and an assertion of defiant confidence. What some people are doing with their words, in the context of phenomena such as Brexit and Trump, is issuing a slap in the face to an Establishment which they believe, with good reason, has failed to serve them. ${ }^{13}$ The content is secondary. When refuted, the refutation may be ignored, or a specific claim retracted and speedily replaced with another that supports the same end. To understand such sayings merely as sayings is, in other words, to miss half their meaning - and is thus bad (political) philosophy.

What, finally, is being done with the word 'post-truth' when it is used? As with the sort of political speech it is used to talk about, talk about post-truth appears to make little sense when taken at face value: it is either totally banal (e.g. if it is observing that politicians sometimes lie or bullshit or that people's beliefs are sometimes distorted by emotion), or it is both wildly audacious and philosophically confused (e.g. conflating narrowmindedness with a form of relativism and attributing both to large swathes of the population on the basis of scant-to-non-existent evidence). But the failure of post-truth talk to

\footnotetext{
${ }^{13}$ This, of course, is not necessarily to defend the particular statements or choices in which anti-Establishment sentiment has found its expression.
} 
make sense just increases the importance of attending to its dimension as action. 'Post-truth' is first and foremost a slur word: it serves to smear its referents, but without contributing to an understanding of their nature or significance. If what I have argued here is right, the term actively contributes confusion. It performs actions of its own: a protest against a protest, a cry for a return to politics as usual, and a distraction from the basic project of trying to understand what is happening. If this is what 'post-truth' talk does, then we would do better to have done with it.

\section{References}

Austin, J. L., 1962. How to Do Things with Words. Oxford University Press. D'Ancona, M., 2017. "Ten Alternative Facts for the Post Truth World”. The Guardian, 12 May. Available at: https://www.theguardian.com/books/2017/may/12/post-truth-worstof-best-donald-trump-sean-spicer-kellyanne-conway [accessed 4 May 2019].

Finlayson, L., 2014. "How to Screw Things with Words". Hypatia: A Journal of Feminist Philosophy, 29 (4): 774-789.

Finlayson, L., 2019. “'I'm Not With Stupid': False Consciousness Stories for a Post-Brexit age". In: C. Fox \& J. Saunders, eds., Media Ethics, Free Speech, and the Requirements of Democracy. London: Routledge: 203-218.

Frankfurt, H., 2005. On Bullshit. Princeton: Princeton University Press.

MacDonald, M., 1941. "The Language of Political Theory". Proceedings of the Aristotelian Society, 41: 91-112.

Nunns, A., 2018. The Candidate: Jeremy Corbyn's Improbable Path to Power. New York and London: OR Books.

Warnock, G. J., 1973. "Some Types of Performative Utterances". In I. Berlin et al., Essays on J. L. Austin. Oxford: Clarendon Press.

Williams, B., 2012 [1972]. Morality. Cambridge: Cambridge University Press.

\section{Biographical Note}

Lorna Finlayson teaches philosophy at the University of Essex. She is the author of The Political Is Political (Rowman \& Littlefield 2015) and $A n$ Introduction to Feminism (CUP 2016). 